\title{
Ranking Regional Air and Water Environmental Degradations
}

\author{
Edward Nissan and George Carter*
}

\begin{abstract}
Utilizing a distance index, state-level pollution data extracted from List and McHone (2000b), states, and regions of the United States are ranked for their air, river, lake, composite water (lake and river), and overall composite (water and air) environmental degradation outputs. For the composite water index, the New England region is ranked first and the Far West region is ranked last. For the overall composite index, the Rocky Mountain region is ranked first and the Mideast region is ranked last.
\end{abstract}

\section{INTRODUCTION}

About the time of the creation in the United States of the Environmental Protection Agency (EPA), Victor (1972) provided one of the first comprehensive studies for the interaction between the economy and the environment. Victor's (1972) approach, using data largely drawn from Canada, estimated the quantities of the environmental pollution generated by the economy. Environmental pollution includes inputs from the environment to industry, such as use of oxygen in the combustion of mineral fuels, as well as industrial outputs that are fed back as waste products into the environment. In the intervening 30 years, partially due to EPA's efforts in providing data and monitoring, a great deal of research was done and much was learned about acceptable standards of environmental inputs and outputs and how to treat a variety of environmental interactions with the economy. Mainstream U.S. regional journals, such as Growth and Change, The Review of Regional Studies, and Papers in Regional Science, as well as journals with diverse topical interests such as the American Economic Review, The Journal of Economic Literature, and Southern Economic Journal, devoted considerable space to regional environmental concerns.

It is not surprising that these journals pay special attention to connecting environmental regulation, which is costly to administer, and its effect on various facets of business interests, such as profitability and competitiveness. Jaffe et al. (1995) quote some impressive numbers for environmental accomplishments and costs. For instance, on the side of accomplishment, there was a considerable reduction in six major air pollutants. Based on a scale of 100 in 1970, the 1991 aggregate national emissions of six air pollutants: sulfur dioxide $\left(\mathrm{SO}_{2}\right)$, nitrogen oxides $\left(\mathrm{NO}_{\mathrm{x}}\right)$, reactive volatile organic compounds (VOCs), carbon monoxide (CO), total suspended particulates (TSPs), and lead are 73, 99, 62, 50, 39, and 2, respectively, a remarkable overall reduction. The cost is also impressive, ranging in 1992 dollars 
as a percentage of GNP from 0.88 in 1972 to an estimated 2.61 in 2000. Moneywise, again in 1992 dollars, the cost of regulation increased from approximately $\$ 33$ billion in 1972 to an estimated $\$ 185$ billion in 2000.

Chiles, Jr. and Clark (1999) explain that when the relative price of an input rises, the added cost of environmental regulation puts firms located in high input price areas at a competitive disadvantage. Gray (1987) estimated the average industry's productivity slowdown due to regulation at about 30 percent of total. The logical question is how this added cost affects industrial competitiveness in exports. Similarly, the added cost of regulation may discourage foreign direct investment with the United States as well as encourage U.S. companies to invest in countries with lax regulation. The argument is turned around by some advocates who maintain that enactment of stricter environmental regulations enhances productivity, thereby stimulating economic competitiveness because of spillovers of research and development (Jaffe 1986). To these opinions and counter opinions, Jaffe et al. (1995) point to a truth that lies between the two ends of the spectrum. Neither do differences in international environmental regulation pose significant threats to U.S. industrial competitiveness, nor is there evidence that stricter environmental standards improve competitiveness. Two other economic issues relating to environmental regulations and the economy are their effects on growth and domestic plant location. Bartik (1988), based on a sample of Fortune 500 companies, examined whether variation in state environmental regulation has affected the location of manufacturing plants in the states. Bartik did not find any statistically significant effect of state environmental regulations on the location of new branch plants.

The question of pollution control costs also affects households. Shortle and Willett (1986) estimate that the range of cost incidence is $\$ 115$ per year (1.52 percent of base income) for families with income $\$ 10,000$ or less to $\$ 608$ per year ( 0.90 percent of base income) for families with income greater than $\$ 25,000$. On the same theme, Scott, Berger, and Blomquist (1988) provide cost estimates of federal air pollution control requirements for the state of Kentucky for coal production, electric utility rates, and manufacturing costs and employment. For electricity, the real cost of abatement increased by 32.4 percent from 1980 to 1984 . Employment in Kentucky manufacturing declined by a mere 444 employees due to environmental abatement costs out of a total decline of 30,871 .

Examples of the array of topics relating other economic issues with the environment take the shape of preserving historic buildings and assessing the viability of tourism and its impact on the environment, as was done by West and Roy (1998). Thampapillai et al. (1998) provide an analysis of the allowance for depreciation of environmental capital in macroeconomic models. Bowers and Inman (2000) provide a classification of environmental strategies for corporate incentives.

Regional environmental issues receive a great deal of attention in countries outside the United States as well. For instance, Hekelova $(1998,1999,2000)$ provides detailed and interesting assessment for management and control of environmental degradation. Important facets of quality management and environmental 
management, according to Hekelova, are the management culture, motivation and communication, and ethical behavior. In the United States, these functions are overseen on local, state, and regional levels by the EPA as mandated by Congress, and in the same manner as suggested by Hekelova. In addition, List and McHone (2000b) describe how the EPA monitors environmental air and water emissions to enhance compliance with established regulations.

In fact, Growth and Change published in 1995 a special issue on wilderness areas, containing such topics as conserving biological diversity and the conflicting missions between wildlife management, surface mining, and regional planning. Another special issue by Growth and Change on industry and the environment was published in 1997. The themes tackled, according to Maclaren and Macpherson (1997), were self-interest due to environmental-industrial interface and the role played by public policy in the development of this interface. In particular, Dobilas and Macpherson (1997) explore the role of environmental factors in allocation decisions of European and North American multinational corporations and accountability of firms for environmental standards. Dupuy (1997) tackles the question of how environmental policy affects technology diffusion by explaining the options of environmental regulations and standards, economic instruments, and voluntary compliance. The first of these are methods of government interventions while the latter are for self-regulating firms.

Despite such a variety of research, Cumberland (2000), echoing Isserman (1993), clearly points to the opportunities missed and still available for regional science to expand its analytical base to include further environmental issues, and he projects that environmental analysis as a regional science research has a healthy growth potential. There are many such examples broadly related to the environment, such as impact of airport noise on property values (Espey and Lopez 2000) and impact on residential housing prices of location near nuclear power plants (Clark et al. 1997).

While the literature cited above attests to the richness of topics at the micro level, this paper investigates in two ways the aggregate patterns of environmental quality at the state level within the United States. The first is to construct indexes for ranking individual states, and the second is to identify differences in regional environmental degradation of the air and water. The regional dimension refocuses attention on the enduring historical disparity for the evaluation of regions' economies. The investigation will shed some light on the comparative place of pollution among the states and regions.

This research focuses on ranking the states for environmental pollution output, as there is significant variation in pollution control across the states. This is especially true as a consequence of the perhaps sound Reagan administration federalism policy of relegating enforcement to individual states. However, Manne and Richels (1991) explained that uniform regulations could be counterproductive because of differences among states. Cumberland (1980), during the then early days of the Reagan administration, noted that administration's policy of reducing 
federal regulation, returning the administration of the environment to the states, and relying on market decisions. According to Kraft and Vig (1990), that indeed was what happened in the 1980s. Many EPA programs were curtailed because of deep cuts in their budgets.

The data for environmental quality were obtained from List and McHone (2000b), who gathered the data from EPA for air and from EPA's National Water Quality Inventory Report to Congress for rivers and lakes. The data are composed of three measures: (1) annual percentage of ozone monitors for the period 1993 to 1997 that had at least one reading exceeding Federal National Air Quality standards (defined as the occurrence of a monitor reading of $0.12 \mathrm{ppm}$ [parts per million] for a one-hour period); (2) biennial impaired miles of rivers for the period 1986 to 1994; and (3) biennial impaired acres of lakes for the period 1986 to 1994. The water data were gathered from surveys of rivers and lakes, excluding bayous and swamps. A river or lake is deemed impaired if pollutants, such as metals, oxygendepleting substances, or bacteria, cause a river or lake to be deemed partially supporting or not supporting designated uses, such as swimming, support of aquatic life, and drinking water supply. Note that impaired river miles or lake acres are divided by the corresponding totals surveyed to produce uniform measures for interstate comparisons. The data are for the 48 contiguous states.

\section{AN INDEX FOR THE ENVIRONMENT}

Indicator data are utilized in a variety of ways to construct composite indexes by which entities are ranked on a single scale. Among these is unweighted rank, a device whereby the entities are ranked according to their actual score, with the best score receiving the rank 1 and so on down the line. No use is made of the actual values-only their rank. A second approach, employed, for instance, by the World Bank (1996) to rate countries for economic integration, is the use of a common scaling device of the indicators by means of the transformation $Z_{i}=\left(X_{i}-M\right) / S$, where $X_{i}$ is an actual observation, $M$ is the mean, and $S$ is the standard deviation. The variable $Z$ has a mean equal to zero and a standard deviation equal to one. An index $I$ is obtained as the average of the negative and positive deviations $Z_{i}$. The values of the index, therefore, may be negative, positive, or zero. Note that the point of reference is the mean.

A third approach, which is based on the concept of distance, is used by the United Nations Development Program (UNDP 2000) and is called the Human Development Index (HDI). The HDI includes three socioeconomic variables and has been in use since 1990 to assess countries for their citizens' quality of life by means other than GNP per capita. The rationale is to account for social and human welfare criteria. Some countries do not translate their comparatively high income into commensurate levels of well-being.

For some country $j, \mathrm{HDI}$ is formally defined as

$$
I_{i j}=\left(X_{i j}-\min _{j} X_{i j}\right) /\left(\max _{j} X_{i j}-\min _{j} X_{i j}\right), 0 \leq I_{i j} \leq 1,
$$


where $I_{i j}$ is called the ith dimension index of human performance for country $j$. The ith dimension index is treated as a relative concept because the variables are scaled to range between zero and one. $X_{i j}$ is the actual value of the ith variable for country $j$, and $\min _{j} X_{i j}$ is the actual minimum value among the countries. Max $X_{i j}$ is a subjectively chosen desired value of the ith variable. Country j's performance is assessed on the basis of life expectancy, adult literacy, and the logarithm of purchasing power adjusted GDP per capita. The composite score for country $j$ is obtained as the average of the three components. It also ranges between zero and one, the closer to one the better. The index has been used in research as a preferred measure of development (as was done by Mbaku 1997). On the introduction of HDI, Bhanojirao (1991), McGillivray (1991), and Hopkins (1991) wrote detailed assessments of its merits.

For the purpose of this paper, let

$$
\begin{aligned}
& X_{1}=\text { ozone exceedances (percent), } \\
& X_{2}=\text { rivers impaired (miles), } \\
& X_{3}=\text { lakes impaired (acres). }
\end{aligned}
$$

Identify for each variable the $\max _{j} X_{i j}$ and $\min _{j} X_{i j}$ values, where $\max _{j} X_{i j}$ and $\min _{j} X_{i j}$ are the maximum (highest) and minimum (lowest) air and water effluent outputs. So, the state with the smallest number is ranked first, the best possible. The index, therefore, places state $j$ in a range for variable $i, i=1,2,3$, where " 1 " indicates the air index, " 2 " indicates the river index, and " 3 " indicates the lake index. Thus, $\mathrm{I}_{1 \mathrm{j}}$, $I_{2 j}$, and $I_{3 j}$ are the transformed indexes by Equation 1 of states' scores of air, river, and lake environmental effluents.

Two composite indexes are also generated. One for water,

$$
I_{(w) j}=1 / 2\left[I_{2 j}+I_{3 j}\right] \text {, }
$$

and one for air and water (overall),

$$
I_{(o) j}=1 / 2\left[I_{1 j}+I_{(w) j}\right] \text {. }
$$

Therefore, there are five indexes, three of which are simple (air, river, lake) and two of which are composite (water, overall). For the environment effluent index as adopted in this paper, the values of the index range between 0.0 , indicating that a state had the best performance, to 1.0, indicating that a state had the worst performance, in reverse of the way the HDI is constructed (where the higher the value, the better is the performance).

For instance, the states of Idaho, Iowa, Minnesota, Montana, North Dakota, Nebraska, Nevada, Vermont, and Wyoming had a 0 percent ozone exceedance. Therefore, the ozone data for these states are used as $\min _{\mathrm{j}} \mathrm{X}_{\mathrm{ij}}$ in Equation 1. Hence, the simple index score for air for these states will be zero. Connecticut, on the other hand, had 86.0 percent ozone exceedance; thus, 86.0 percent is used for $\max _{\mathrm{j}} \mathrm{X}_{\mathrm{ij}}$ in Equation 1, and the index score will be one. Index scores for the remaining states will range between the two extremes, zero and one. For the simple indexes for river and lake, Maine, with 1.9 percent of its rivers impaired, and Indiana, with 0.20 percent of its lakes impaired, had the minimum scores, and these 
scores will be used in Equation 1. The respective maximums were attained by Iowa, with 89.7 percent of its rivers impaired, and Illinois, with 86 percent of its lakes impaired; therefore, their scores will be used in Equation 1.

Two main features of this index are worth mentioning. The first feature is that the entities are compared to a leader that constitutes the best scores of the variables rather than the mean. For the study at hand, aside from perceiving how many states are ahead of a given state, the index score for a state is interpreted as the relative metric distance a state has to travel to reach the best state score (the leader) in air, river, and lake environmental effluent outputs. This aspect makes comparisons among states somewhat more meaningful than comparisons made on ranking alone, in the sense that two states may be very close to the leader in environmental pollution output, yet their ranks could be wide apart. The second feature tends to overcome this deficiency because the resulting index is a metric measure, making statistical inferences possible. One can also interpret the index broadly in terms of convergence and divergence (List 1999). Convergence occurs when a state with an index value lying below the level of the reference state exhibits faster movement, and hence its index level tends to catch up to the reference state's. In other words, the disparity in index levels closes through time. Divergence, by contrast, means that the disparity widens, at least temporarily.

\section{EMPIRICAL RESULTS}

\section{Comparisons by States}

Table 1 displays the results of the simple indexes and composite indexes by state. The simple indexes, denoted by $I_{i}, i=1,2,3$ are computed from Equation 1 for air, river, and lake. The composite index for water $\mathrm{I}_{(\mathrm{w})}$ is computed by Equation 2 , and the overall composite index $\mathrm{I}_{(\mathrm{o})}$ by Equation 3 . In all cases, next to the indexes are the ranking, denoted by $R$, of states according to these indexes. Note that because the index values range from zero to one, the smaller the magnitude the closer the individual state is to the minimum score. In other words, the numbers define how far a given individual state falls short of the leader state, defined as attaining minimum levels of air, river, lake, water, and overall pollution exposure.

In Table 1, aside from the rankings of the indexes, the numbers provide each state's shortfall in reaching the best score. A challenge for every state, therefore, is to find ways to reduce its shortfall. For instance, for the air index, Idaho, Iowa, Minnesota, Montana, North Dakota, Nebraska, Nevada, Vermont, and Wyoming are tied for the minimum index zero score, and thus receive the rank 1. Connecticut, on the other hand, ranked 47th with a maximum index score of one. Connecticut, therefore, has the biggest challenge in aiming for the minimum percentage of ozone exceedance. Not so challenging is the situation for New Mexico, which needs to overcome only 5.6 percent of the distance to attain the minimum. Maryland, with score 0.833 , has to overcome 83.3 percent of the distance. 


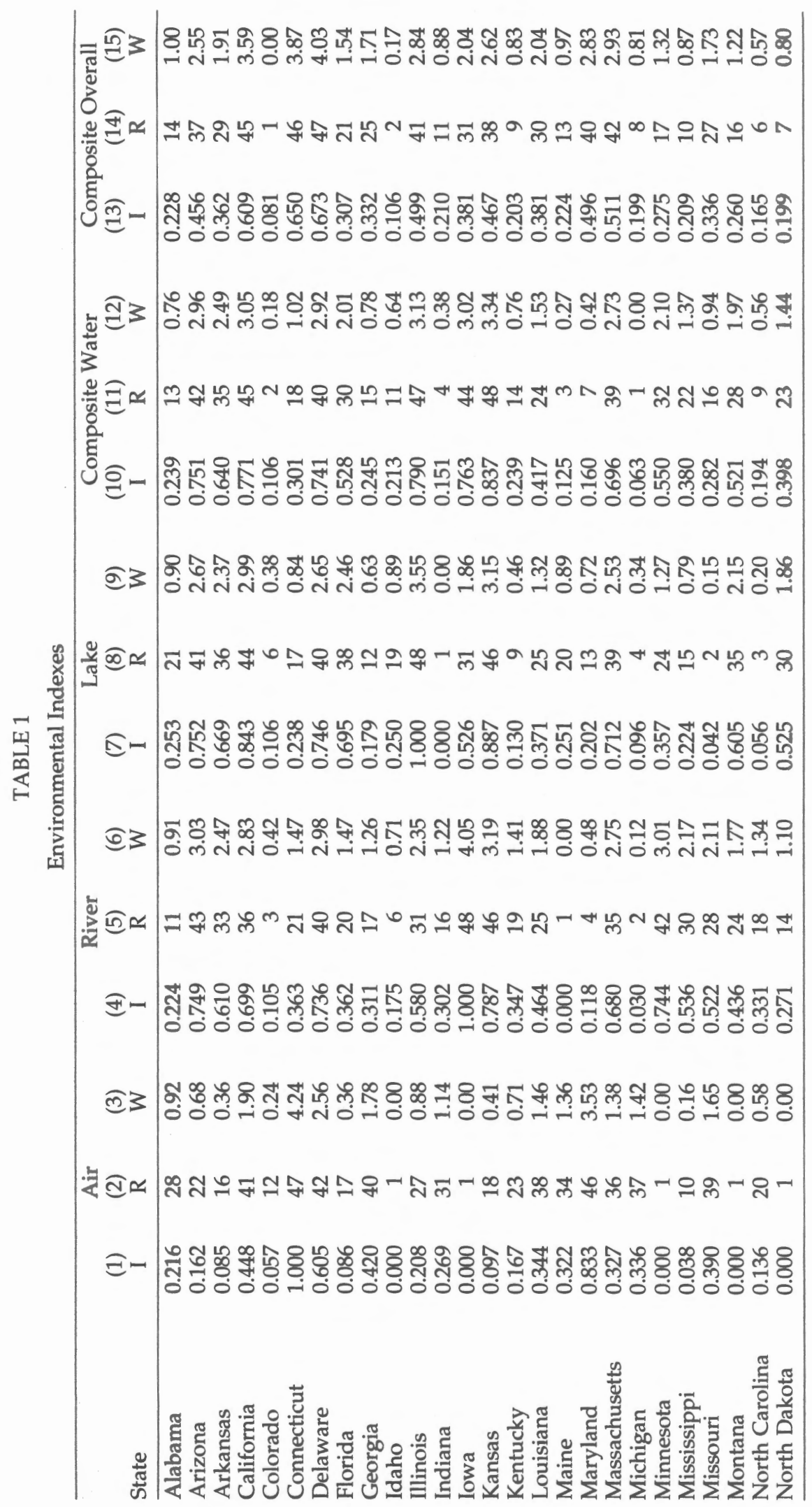




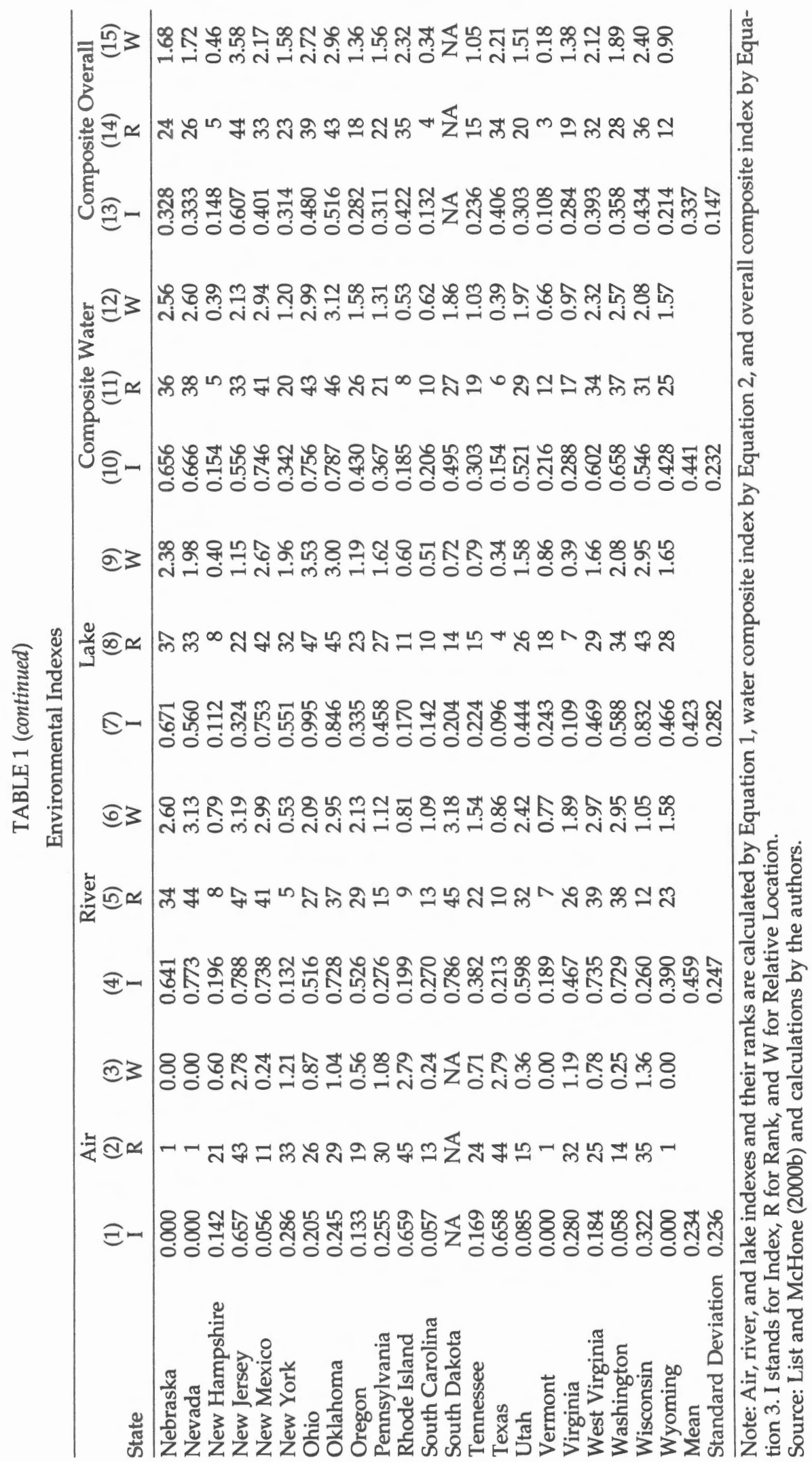


For the river index, Maine captures the minimum spot with a score of 0 , and Iowa is rated the maximum with a score of 1.00 (possibly because the Mississippi River runs along its eastern boundary and the Missouri River runs along its western boundary, as pointed out by a reviewer of this paper). The minimum and maximum states for the lake index are Indiana and Illinois, respectively. For the composite indexes, on the other hand, Michigan is in the lead for the minimum water and Colorado for the minimum overall, while Kansas and Delaware are in the positions at the other extreme.

The water composite index as generated by Equation 2 averages the values of the component (river, lake) simple indexes provided in Columns 4 and 7, with results shown in Column 10. Thus, with an index score of 0.063 , Michigan is ranked first for composite water quality, and Kansas, with a score of 0.837 , is ranked last. The overall composite environmental index as calculated by Equation 3 averages the simple index of air (Column 1) and composite index of water (Column 10), producing the results shown in Column 13. Here, Colorado, with an index score of 0.081 , is ranked first, and Delaware, with a score of 0.673 , is ranked last. Therefore, Colorado has to overcome 8.1 percent of the two-dimensional distance to arrive at the central point $(0.000,0.063)$, while Delaware has to overcome 67.3 percent of the distance.

Columns $3,6,9,12$, and 15 of Table 1 provide the relative location, $\mathrm{W}$, of an index value to the leader point as multiples of the standard deviation, where

$$
\mathrm{W}=\left(\mathrm{I}_{\mathrm{j}}-\mathrm{I}_{0}\right) / \mathrm{S}_{\mathrm{I}} \text {. }
$$

$\mathrm{I}_{\mathrm{j}}$ and $\mathrm{I}_{0}$ stand for state $\mathrm{j}$ and the leader state scores for an index (air, river, lake, water, overall) and $\mathrm{S}_{\mathrm{I}}$ is the U.S. standard deviation of the index. The W-score can be interpreted as the number of standard deviations that $\mathrm{I}_{j}$ is from the leader $\mathrm{I}_{0}$. Checking, for instance, the distance between Mississippi, ranked 10th for the overall composite index with a score of 0.209 , and Colorado, ranked 1st with a score of 0.081 , the $\mathrm{W}$-value is 0.87 , which is relatively small. On the other hand, comparing Texas, with an overall composite index score of 0.406 and $W$-value of 2.21 , with Mississippi shows that Texas has substantially more environmental degradation than Mississippi.

Supported by the results of computations of $W$ by Equation 4, it is deemed appropriate to combine the $\mathrm{W}$-values for individual states into groups. For each of the five indexes, five groupings were established to classify states: those that fall within $0 \leq W \leq 1,1<W \leq 2,2<W \leq 3,3<W \leq 4$, and $W>4$. The summarization is provided in Table 2, where the ranges of the groupings for the five indexes are shown in Column 1. Column 2 of Table 2 gives the number of states falling into each interval of W, followed in Column 3 by each of the five state index ranks. Column 4 lists the states that fall beyond two standard deviations from the best score as measured by W. Connecticut for the air index, Iowa for the river index, and Delaware for the composite overall index, had the distinctions of being more than four standard deviations away from the best score. 
TABLE 2

Relative Location, W, of States and their Index Ranks for Environmental Outputs

\begin{tabular}{|c|c|c|c|}
\hline W & $\begin{array}{l}\text { Number } \\
\text { of States }\end{array}$ & $\begin{array}{l}\text { Index } \\
\text { Ranks }\end{array}$ & States \\
\hline \multicolumn{4}{|l|}{ Air } \\
\hline$\overline{0-1}$ & 28 & $1-28$ & \\
\hline $1-2$ & 13 & $29-41$ & \\
\hline $2-3$ & 4 & $42-45$ & DE,NI,TX,RI \\
\hline $3-4$ & 1 & 46 & MD \\
\hline$>4$ & 1 & 47 & CT \\
\hline \multicolumn{4}{|c|}{$\underline{\text { River }}$} \\
\hline $0-1$ & 11 & $1-11$ & \\
\hline $1-2$ & 15 & $12-26$ & \\
\hline $2-3$ & 15 & $27-41$ & $\begin{array}{l}\mathrm{OH}, \mathrm{MO}, \mathrm{OR}, \mathrm{MS}, \mathrm{IL}, \mathrm{UT}, \mathrm{AR}, \mathrm{NE} \text {, } \\
\text { MA,CA,OK,WA,WV,DE,NM }\end{array}$ \\
\hline $3-4$ & 6 & $42-47$ & $\mathrm{MN}, \mathrm{AZ}, \mathrm{NV}, \mathrm{SD}, \mathrm{KS}, \mathrm{NJ}$ \\
\hline$>4$ & 1 & 48 & IA \\
\hline \multicolumn{4}{|c|}{ Lake } \\
\hline $0-1$ & 21 & $1-21$ & \\
\hline $1-2$ & 12 & $22-33$ & \\
\hline $2-3$ & 11 & $34-44$ & $\begin{array}{l}\text { WA,MT,AR,NE,FL,MA, } \\
\text { DE,AZ,NM,WI,CA }\end{array}$ \\
\hline $3-4$ & 4 & $45-48$ & $\mathrm{OK}, \mathrm{KS}, \mathrm{OH}, \mathrm{IL}$ \\
\hline$>4$ & 0 & & \\
\hline \multicolumn{4}{|c|}{ Composite Water } \\
\hline $0-1$ & 17 & $1-17$ & \\
\hline $1-2$ & 12 & $18-29$ & \\
\hline $2-3$ & 14 & $30-43$ & $\begin{array}{l}\text { FL,WI,MN,NJ,WV,AR,NE, } \\
\text { WA,NV,MA,DE,NM,AZ,OH }\end{array}$ \\
\hline $3-4$ & 5 & $44-48$ & $\mathrm{IA}, \mathrm{CA}, \mathrm{OK}, \mathrm{IL}, \mathrm{KS}$ \\
\hline$>4$ & 0 & & \\
\hline \multicolumn{4}{|c|}{ Composite Qverall } \\
\hline$\overline{0-1}$ & 13 & $1-13$ & \\
\hline $1-2$ & 16 & $14-29$ & \\
\hline $2-3$ & 14 & $30-43$ & $\begin{array}{l}\text { LA,IA,WV,NM,TX,RI,WI, } \\
\text { AZ,KS,OH,MD,IL,MA,OK }\end{array}$ \\
\hline $3-4$ & 3 & $44-46$ & $\mathrm{NJ}, \mathrm{CA}, \mathrm{CT}$ \\
\hline$>4$ & 1 & 47 & $\mathrm{DE}$ \\
\hline
\end{tabular}

Source: Table 1.

Thus, Table 2 can be used as a guide for state policies. States that belong to the grouping of $3<W \leq 4$ or higher have a bigger challenge in their pollution abatement strategies than those grouped under the classification $2<W \leq 3$ and so on. Furthermore, interdependent states in the East, such as Delaware, New Jersey, Rhode Island, Maryland, and Connecticut, known for their extensive industrial base, fall within $2<W \leq 3$ or higher for the air index as well as the composite overall index.

\section{Impacts of Socioeconomic and Demographic Forces on State Pollution}

State overall pollution index scores can be thought of as a function of key socioeconomic and demographic variables. Variables such as state per capita income, state per capita expenditure on pollution, urbanization, population density, and the like may serve as determinants of the level of state pollution, in their own right as well as proxies for a host of other variables. For instance, state per 
capita income may stand as a proxy for the composition of output and policies related to regulation of the environment.

Fifteen relevant explanatory variables were selected. Statistical tools of linear correlation and regression between a variable and the composite overall environmental index were used to establish relationships. Table 3 is a display of the results of the fifteen regressions where the independent variable is denoted by $X_{i}$, $i=1,2,3, \ldots, 15$. The composite overall index, denoted by $Y$, is the dependent variable. The linear regressions, therefore, take the form

$$
\mathrm{Y}=\mathrm{b}_{0}+\mathrm{b}_{1} \mathrm{X}_{\mathrm{i}} \text {, }
$$

where $i$ ranges between 1 and 15 .

TABLE 3

Correlation and Regression Results of Socioeconomic and Demographic Impacts on Pollution (Dependent Variable - Composite Overall Index)

\begin{tabular}{lccc}
\hline Variable (by state) & $\mathrm{b}$ & $\mathrm{p}$-value & $\mathrm{r}$ \\
\hline X1: 1970 Per Capita Environmental Expenditures & 0.012000 & 0.861 & 0.026 \\
X2: 1980 Per Capita Environmental Expenditures & 0.005000 & 0.061 & 0.275 \\
X3: 1986 Per Capita Environmental Expenditures & -0.000819 & 0.427 & -0.119 \\
X4: 1997 Per Capita Environmental Expenditures & -0.000697 & 0.126 & -0.227 \\
X5: 1997 Per \$1000 Environmental Expenditures & -0.051050 & 0.195 & -0.192 \\
X6: 1999 Population & 0.000007 & 0.049 & 0.289 \\
X7: 1999 Population Density & 0.000316 & 0.000 & 0.529 \\
X8: 1998 Metropolitan Population Percent & 0.003733 & 0.000 & 0.519 \\
X9: 1990 Urban Population Percent & 0.005666 & 0.000 & 0.562 \\
X10: 1998 Average Annual Pay & 0.000016 & 0.000 & 0.495 \\
X11: 1999 Per Capita Personal Income & 0.000015 & 0.002 & 0.436 \\
X12: 1999 Per Capita Disposable Personal Income & 0.000019 & 0.004 & 0.416 \\
X13: 1997 Taxes & 0.000129 & 0.002 & 0.432 \\
X14: 1999 High School Graduates Percent & -0.002692 & 0.606 & -0.077 \\
X15: 1999 College Graduates Percent & 0.007386 & 0.110 & 0.236 \\
\hline
\end{tabular}

Source: Calculations from Table 1 by Equation 5 .

When the correlation coefficient $r$ in Table 3 is positive, the implication is that higher values of the variable $X_{i}$ coincide with higher values of the composite overall index, which implies higher environmental effluent emissions. The reverse is true if $r$ is negative. The list in Table 3 indicates that among the fifteen variables, eleven are positive and contribute to increases in environmental effluent outputs. Four variables- $X_{3}, X_{4}, X_{5}$, and $X_{14}$-have negative correlations.

Table 3 also provides the linear regression slopes $\left(b_{i}\right)$ of Equation 5 , along with their $p$-values. The $p$-values range between 0.000 and 0.861 . Eight variables are significant at the $5 \%$ level or better: $\mathrm{X}_{6}, \mathrm{X}_{7}, \mathrm{X}_{8}, \mathrm{X}_{9}, \mathrm{X}_{10}, \mathrm{X}_{11}, \mathrm{X}_{12}$, and $\mathrm{X}_{13}$. Thus, the most important explanatory variables are 1999 Population, 1999 Population Density, 1999 Metropolitan Population Percent, 1990 Urban Population Percent, 1998 Average Annual Pay, 1999 Per Capita Personal Income, 1999 Per Capita Disposable Personal Income, and 1997 Taxes. In addition, these variables are related to other factors (proxies) that also contribute to environmental degradation. The variables with the least explanatory power, those with relatively large $\mathrm{p}$-values, are $X_{1}, X_{2}, X_{3}, X_{4}, X_{5}, X_{14}$, and $X_{15}$. The results in these analyses support the prevailing 
understanding of the relationships among the environment, the economy, and demography. Certainly, urbanization is a key determinant of levels of pollutionurbanization in its own right, as well as urbanization serving as a proxy for industrial activity.

Looking deeper into the results of Table 3, at, for instance, state expenditures $X_{1}, X_{2}$, and $X_{3}$ on which $Y$ (the index) is regressed, though not statistically significant, the change in sign between $X_{1}(1970)$ and $X_{3}(1986)$ indicates that per capita expenditures by states on the environment started to have effects in the latter period. $X_{4}$ and $X_{5}$, related to 1997 expenditure per capita and per $\$ 1,000$, respectively, though not statistically significant, display the proper negative sign. Therefore, overall, the results obtained from regressing the environmental index on expenditures provide a conclusion that environmental expenditure indeed may have some effect on reducing pollution.

The explanatory variables $\mathrm{X}_{6}$ through $\mathrm{X}_{9}$, which depict population congestion looked at from different points of view, reveal a strong association between population and the production of effluents, as is expected. Similarly, the explanatory variables $X_{10}$ through $X_{13}$ are proxies for economic activities: the more the activity, the more is the production of effluents. The high statistical significance of these variables along with the proper positive signs give a conclusive interpretation that economic activity is responsible for pollution. Finally, the education variables $X_{14}$ and $X_{15}$, both not statistically significant, indicate that education has perhaps little effect on the environment.

\section{Comparisons by Regions}

United States regions differ in many respects. Two such differences, as pointed out by Clark et al. (1997), are related to the distinctness of the composition of industries and the bias, due to transportation costs, for regional export basket. As such, it is expected that regional environmental pollution outputs also differ. Table 4 shows index summaries for regional environmental effluents of air, river, and lake, as well as the composite indexes of water and overall as obtained from Equations 1-3. The regions are classified according to the Bureau of Economic Analysis (see Appendix for lists of states in the eight regions). Shown are the mean of a region, calculated as the simple average of the member states, and the standard deviation of each of the indexes. The table indicates that both the means and the standard deviations differ among regions. It is possible to ascertain whether the apparent differences between indexes' regional means are statistically significant and, if so, whether the regions can be grouped into sets with indistinguishable differences. For this purpose, analysis of variance, which tests for regional equality of means, was performed for the indexes.

The results are shown in Table 5. For the lake index, the null hypothesis of equality of regional means with p-value $=0.255$ is accepted, indicating that no perceptible difference in mean impaired lake acres among the eight regions is observed. For the water index, the rejection is at $8 \%$ significance, higher than the 
customary 5\%. For the air, river, and composite indexes, the null hypothesis of equality of regional means must be rejected. The p-values of the corresponding Fratios are very small, ranging between $p$-value $=0.003$ and $p$-value $=0.021$.

TABLE 4

Descriptive Statistics of Environmental Indexes by Regions

\begin{tabular}{|c|c|c|c|c|c|c|c|c|c|c|}
\hline \multirow{2}{*}{ Region } & \multicolumn{5}{|c|}{ Air } & \multicolumn{5}{|c|}{ River } \\
\hline & M & $S$ & $\mathrm{CV}$ & Min & $\operatorname{Max}$ & M & $\mathrm{S}$ & CV & Min & Max \\
\hline$\overline{\mathrm{NE}}$ & 0.408 & 0.365 & 0.895 & 0.000 & 1.000 & 0.271 & 0.231 & 0.851 & 0.000 & 0.680 \\
\hline ME & 0.527 & 0.249 & 0.472 & 0.255 & 0.833 & 0.410 & 0.328 & 0.800 & 0.118 & 0.788 \\
\hline GL & 0.268 & 0.062 & 0.230 & 0.205 & 0.336 & 0.337 & 0.220 & 0.651 & 0.030 & 0.580 \\
\hline PL & 0.081 & 0.156 & 1.926 & 0.000 & 0.390 & 0.679 & 0.232 & 0.342 & 0.271 & 1.000 \\
\hline SE & 0.182 & 0.117 & 0.644 & 0.038 & 0.420 & 0.420 & 0.149 & 0.354 & 0.224 & 0.735 \\
\hline SW & 0.280 & 0.264 & 0.943 & 0.056 & 0.658 & 0.607 & 0.263 & 0.433 & 0.213 & 0.749 \\
\hline RM & 0.028 & 0.040 & 1.412 & 0.000 & 0.085 & 0.341 & 0.200 & 0.588 & 0.105 & 0.598 \\
\hline FW & 0.160 & 0.200 & 1.251 & 0.000 & 0.448 & 0.682 & 0.108 & 0.159 & 0.526 & 0.773 \\
\hline US & 0.234 & 0.236 & 1.010 & 0.000 & 1.000 & 0.459 & 0.247 & 0.539 & 0.000 & 1.000 \\
\hline \multirow{2}{*}{ Region } & \multicolumn{5}{|c|}{ Lake } & & & & & \\
\hline & IVI & 3 & C & IVIn & $\operatorname{lnax}$ & & & & & \\
\hline NE & 0.288 & 0.215 & 0.747 & 0.112 & 0.712 & & & & & \\
\hline $\mathrm{ME}$ & 0.456 & 0.209 & 0.458 & 0.202 & 0.746 & & & & & \\
\hline GL & 0.585 & 0.496 & 0.848 & 0.000 & 1.000 & & & & & \\
\hline PL & 0.459 & 0.285 & 0.621 & 0.042 & 0.887 & & & & & \\
\hline $\mathrm{SE}$ & 0.293 & 0.214 & 0.729 & 0.056 & 0.695 & & & & & \\
\hline SW & 0.612 & 0.347 & 0.567 & 0.096 & 0.846 & & & & & \\
\hline RM & 0.374 & 0.196 & 0.524 & 0.106 & 0.605 & & & & & \\
\hline FW & 0.581 & 0.208 & 0.358 & 0.335 & 0.843 & & & & & \\
\hline \multirow[t]{2}{*}{ US } & 0.423 & 0.282 & 0.666 & 0.000 & 1.000 & & & & & \\
\hline & \multicolumn{5}{|c|}{ Water } & \multicolumn{5}{|c|}{ Composite } \\
\hline Region & M & $S$ & $\mathrm{CV}$ & Min & Max & $\mathrm{M}$ & $S$ & $\overline{C V}$ & Min & $\operatorname{Max}$ \\
\hline $\mathrm{NE}$ & 0.280 & 0.213 & 0.761 & 0.125 & 0.696 & 0.344 & 0.218 & 0.632 & 0.108 & 0.650 \\
\hline ME & 0.433 & 0.222 & 0.512 & 0.160 & 0.741 & 0.480 & 0.166 & 0.345 & 0.311 & 0.673 \\
\hline GL & 0.461 & 0.338 & 0.733 & 0.063 & 0.790 & 0.365 & 0.148 & 0.406 & 0.199 & 0.499 \\
\hline PL & 0.569 & 0.198 & 0.348 & 0.282 & 0.837 & 0.331 & 0.091 & 0.276 & 0.199 & 0.467 \\
\hline SE & 0.357 & 0.157 & 0.440 & 0.194 & 0.640 & 0.269 & 0.087 & 0.322 & 0.132 & 0.393 \\
\hline SW & 0.609 & 0.304 & 0.499 & 0.154 & 0.787 & 0.445 & 0.054 & 0.121 & 0.401 & 0.516 \\
\hline RM & 0.358 & 0.189 & 0.529 & 0.106 & 0.521 & 0.193 & 0.096 & 0.499 & 0.081 & 0.303 \\
\hline FW & 0.632 & 0.144 & 0.227 & 0.431 & 0.771 & 0.396 & 0.146 & 0.369 & 0.282 & 0.609 \\
\hline US & 0.441 & 0.232 & 0.525 & 0.063 & 0.837 & 0.337 & 0.147 & 0.436 & 0.081 & 0.673 \\
\hline
\end{tabular}

Note: M, S, CV, Min, and Max denote mean, standard deviation, coefficient of variation, minimum, and maximum, respectively.

Source: Calculations by authors using Equations 1 and 2.

TABLE 5

Analysis of Variance for Equality of Regional Environmental Means

\begin{tabular}{lcc}
\hline Variable & $\mathrm{F}$ & $\mathrm{p}$-Value \\
\hline Air Index & 3.75 & 0.003 \\
River Index & 3.11 & 0.010 \\
Lake Index & 1.34 & 0.255 \\
Water Index & 1.99 & 0.080 \\
Composite Index & 2.72 & 0.021 \\
\hline
\end{tabular}

Source: Calculations by the authors. 
On calculating $95 \%$ confidence intervals for the indexes by the method of Least Significant Difference (see Ostle and Malone 1988), it is possible to separate the regions for significant differences in their means in Table 4. For this purpose, the means are ordered from smallest to largest, remembering that the smaller values correspond to better roles in the environment. For ease of presentation, the regions are denoted by abbreviations as follows: New England (NE), Mideast (ME), Great Lakes (GL), Plains (PL), Southeast (SE), Rocky Mountain (RM), and Far West (FW).

The regional lineups are:

\begin{tabular}{|c|c|c|}
\hline Air: & [RM,PL, I FW,SE, | GL,SW, I NE,ME] & $p$-value $=0.003$ \\
\hline River: & {$[\mathrm{NE}, \mathrm{GL}, \mathrm{RM},|\mathrm{ME}, \mathrm{SE},| \mathrm{SW}, \mathrm{PL}, \mathrm{FW}]$} & $\mathrm{p}$-value $=0.010$ \\
\hline Lake: & [NE,SE,RM,ME,PL,FW,GL,SW] & p-value $=0.255$ (no sig. diff.) \\
\hline Water: & [NE,SE,RM, | ME,GL, | PL,SW,FW] & $\mathrm{p}$-value $=0.080$ \\
\hline Overall: & {$[\mathrm{RM}, \mathrm{I} \mathrm{SE}, \mathrm{PL}, \mathrm{NE}, \mathrm{GL}, \mathrm{FW}, \mathrm{I} \mathrm{SW}, \mathrm{ME}]$} & $\mathrm{p}$-value $=0.021$ \\
\hline
\end{tabular}

The vertical bars separate the regions into subsets in which regional means do not differ significantly. It is possible, therefore, to conclude that the regions with the least environment degradations for air are the Rocky Mountain and the Plains regions. The regions with the most are the New England and the Mideast, which include states, such as New Jersey, Connecticut, Massachusetts, and Rhode Island, with poor air index scores. These states are highly industrialized, with factories generating ozone-depleting chemicals. For the river index, the Southwest, the Plains, and the Far West regions are identified as among the worst. Similarly for the other indexes, it is possible to identify the regions that have the least or the most environmental degradation. Note for the lake index that no slashes in the above scheme are present because the analysis of variance could not distinguish differences among the regions. Finally, the regions with the most overall environmental degradations are the Mideast and the Southwest, with the Far West region significantly further behind.

\section{CONCLUDING REMARKS}

As Dupuy (1997) observed, industries are faced with the growing awareness of environmental protection in response to regulatory and nonregulatory forces. The focus of this paper was a profile of states' air, river, lake, water, and overall environmental pollution by constructing indexes based on the concept of distance. The results indicate a large degree of variation among the states and regions due perhaps to differences in regulatory rigor among states. The effect of such differences can potentially influence business location, as indicated by List and McHone (2000a) in their study of manufacturing location decisions in the state of New York during 1980-1990. They found that manufacturers in pollutionintensive sectors were discouraged from locating in counties with stringent environmental regulations. As a consequence, a "browning" process took place. Areas with less pollution and lighter pollution controls attracted firms away from areas with heavier pollution and heavier pollution controls, thereby giving the latter a 
break from further destructive activity. On the whole, this may represent a Pareto improvement. Their findings for the locational decisions in New York counties may be broadened to understand policy trends at the state level. Henderson (1996) hinted at such trends. As related to this research, states in the low ranges of W, as shown in Table 2, could become target locations for industries known for their extensive air and water effluents.

The decision problem for policy makers involves trade-offs between maximizing the net benefits of environmental controls and the least-cost method of achieving them. Other considerations, as pointed out by Hahn and Stavins (1992), include overall effectiveness, ease of implementation, equity, information requirements, monitoring and enforcement capability, political feasibility, and clarity to the general public. Interdependent with policy decisions for the here and now, as pointed out by Howarth and Norgaard (1992), is the incorporation of the interests of future generations by considering issues of sustainable development. The goal of policy making is the design of an environmental strategy that maximizes overall welfare, including market and nonmarket goods. Oates (1995) points out that restraining levels of pollution can take the form of command-and-control at one extreme and pollution taxes at the other. Whichever route is chosen, the strategy should consider net environmental effluent reduction benefits, such as effects on agricultural yields, human health, and recreation and leisure time, as suggested by Morgenstern (1991).

\section{APPENDIX}

Regions of the contiguous United States according to the Bureau of Economic Analysis are:

1. New England: Maine, New Hampshire, Vermont, Massachusetts, Connecticut, Rhode Island

2. Mideast: New York, Pennsylvania, New Jersey, Delaware, Maryland

3. Great Lakes: Ohio, Michigan, Indiana, Wisconsin, Illinois

4. Plains: Minnesota, Iowa, Missouri, North Dakota, South Dakota, Nebraska, Kansas

5. Southeast: Virginia, West Virginia, North Carolina, South Carolina, Georgia, Florida, Kentucky, Tennessee, Alabama, Mississippi, Arkansas, Louisiana

6. Southwest: Oklahoma, Texas, Arizona, New Mexico

7. Rocky Mountain: Colorado, Wyoming, Montana, Idaho, Utah

8. Far West: Nevada, California, Oregon, Washington

\section{REFERENCES}

Bartik, T.J. "The Effects of Environmental Regulation on Business Location in the United States." Growth and Change 19 (1988), 22-44.

Bhanojirao. V.V. "Human Development Report 1990: Review and Assessment." World Development 19 (1991), 1451-1460. 
Bowers, W.P., and R.A. Inman. "A Taxonomy of Environmental Strategies for Manufacturers." The Southern Business and Economic Journal 23 (2000), 241-262.

Chiles Jr., T.W., and J. Clark. "Environmental Regulation and the Spatial Distribution of Capital Resources." The Review of Regional Studies 29 (1999), 51-62.

Clark, D.E., L. Michelbrink, T. Allison, and W.C. Metz. "Nuclear Power Plants and Residential Housing Prices." Growth and Change 28 (1997), 496-519.

Cumberland, J.H. "Efficiency and Equity in Interregional Environmental Management." The Review of Regional Studies 10 (1980), 1-9.

"Regional Science and Ecological Economics: The Case of Nauru." The Review of Regional Studies 30 (2000), 17-25.

Dobilas, G., and A. Macpherson. "Environmental Regulation and International Sourcing Policies and Multinational Firms." Growth and Change 28 (1997), 7-23.

Dupuy, D. "Technological Change and Environmental Policy: The Diffusion of Environmental Technology." Growth and Change 28 (1997), 49-66.

Espey, M., and H. Lopez. "The Impact of Airport Noise and Proximity on Residential Property Values." Growth and Change 31 (2000), 408-419.

Gray, W.B. "The Cost of Regulation: OSHA, EPA, and the Productivity Slowdown." American Economic Review 77 (1987), 998-1006.

Hahn, R.W., and R.N. Stavins. "Economic Incentives for Environmental Protection: Integrating Theory and Practice." American Economic Review 82 (1992), 464-468.

Hekelova, E. "Quality Improvement in Manufacturing." ISMQCN98 Metrology for Quality Control in Production (1998), Vienna, Austria.

. "Motivation in TQM." Marketing and Quality (1999), Bratislava.

"Firm Culture-An Integrated Element of Quality Management System and Environmental Management System." IMEKO 2000 World Congress (2000), Vienna, Austria.

Henderson, J.V. "Effects of Air Quality Regulation." American Economic Review 86 (1996), 789-813.

Hopkins, M. "Human Development Revisited: A New UNDP Report." World Development 19 (1991), 1469-1473.

Howarth, R.B., and R.B. Norgaard. "Environmental Valuation under Sustainable Development." American Economic Review 81 (1992), 473-477.

Isserman, A.M. "Lost in Space? On History, Status, and Future of Regional Science." The Review of Regional Studies 23 (1993), 1-50.

Jaffe, A.B. "Technological Opportunity and Spillovers of R\&D: Evidence from Firms' Patents, Profits, and Market Value." American Economic Review 76 (1986), 984-1001.

Jaffe, A.B., S.R. Peterson, P.R. Portney, and R.N. Stavins. "Environmental Regulation and the Competitiveness of U.S. Manufacturing: What does the Evidence Tell Us?" The Journal of Economic Literature 33 (1995), 132-163. 
Kraft, M.E., and N.J. Vig. "Environmental Policy from the Seventies to the Nineties: Continuity and Change." In N.J. Vig and M.E. Kraft (eds.) Environmental Policy in the 1990s: Toward a New Agenda. Washington, D.C.: CQ Press, 1990.

List, J.A. "Have Air Pollutant Emissions Converged Among U.S. Regions? Evidence from Unit Root Tests." Southern Economic Journal 66 (1999), 144-155.

List, J.A., and W.W. McHone. "Measuring the Effects of Air Quality Regulations on 'Dirty' Firm Births: Evidence from the Neo- and Mature-Regulatory Periods." Papers in Regional Science 79 (2000a), 177-190.

. "Ranking State Environmental Outputs: Evidence from Panel Data." Growth and Change 31 (2000b), 23-39.

Maclaren. V.W., and A. Macpherson. "Industry and the Environment." Growth and Change 28 (1997), 3-6.

Manne, A.S., and R.G. Richels. "International Trade in Carbon Emission Rights: A Decomposition Procedure." American Economic Review 81 (1991), 135-139.

Mbaku, J.M. "Inequality in Income Distribution and Economic Development: Evidence Using Alternative Measures of Development." Journal of Economic Development 22 (1997), 57-67.

McGillivray, M. "The Human Development Index: Yet Another Redundant Composite Development Indicator?" World Development 19 (1991), 1461-1468.

Morgenstern, R.D. "Toward a Comprehensive Approach to Global Climate Change Mitigation." American Economic Review 81 (1991), 140-145.

Oates, W.E. "Green Taxes: Can We Protect the Environment and Improve the Tax System at the Same Time." Southern Economic Journal 61 (1995), 915-922.

Ostle, B., and L.C. Malone. Statistics in Research. Ames: Iowa State University Press, 1988.

Scott Jr., F.A., M.C. Berger, and G.C. Blomquist. "Impacts of Air Pollution Control Strategies in Kentucky." Growth and Change 19 (1988), 40-55.

Shortle, J.S., and K.D. Willett. "The Incidence of Water Pollution Control Costs: Partial vs. General Equilibrium Computations." Growth and Change 17 (1986), 32-43.

Thampapillai, D.J., S. Warden, M. Larsson, and H.E. Uhlin. "The Environment in Macroeconomic Analysis-Comparisons Between Sweden and the United States." Australasian Journal of Regional Studies 4 (1998), 349-361.

UNDP. Human Development Report 2000. New York: Oxford University Press, 2000.

Victor, P.A. Pollution: Economy and Environment. Toronto: University of Toronto Press, 1972.

West, G.R., and J.R. Roy. "Towards an Interregional Framework for Joint Assessment of Tourism and the Environment." Australasian Journal of Regional Studies 4 (1998), 161-176.

World Bank. Global Economic Prospects and the Developing Countries. Washington, D.C., 1996. 
